\title{
PERBEDAAN MODEL DAN TEORI DALAM ILMU KOMUNIKASI
}

\author{
Bambang A.S. \\ Marketing Communication Department, Faculty of Economic and Communication, BINUS University \\ Jln. K.H. Syahdan No. 9, Palmerah, Jakarta Barat 11480 \\ aa_saputera@binus.ac.id
}

\begin{abstract}
This article aims to describe differences in models and theories of communication and their respective roles. Many students of Communication Studies do not really care because it was considered too elementary. Students tend to focus on the "big things", such as the development of cutting-edge theories and methodologies, which are currently in the direction of qualitative. Fully understand the differences in substantive theory and models, not only will provide clarification, but also understand each scientific term more comprehensively. The study was conducted based on literature study, with critical descriptive writing, it is also expected to give more space in the discussion. Thus, the purpose of writing this article as mentioned above will be sharper and more significant (reaching level universe of discourse).
\end{abstract}

Keywords: models, theory, function theory, function models

\begin{abstract}
ABSTRAK
Artikel ini bertujuan untuk menggambarkan perbedaan model dan teori komunikasi serta perannya masing-masing. Banyak mahasiswa Ilmu Komunikasi tidak terlalu peduli karena dianggap terlalu elementer. Mahasiswa cenderung hanya fokus pada "hal-hal besar", seperti perkembangan teori mutakhir dan metodologi, yang kini sedang banyak ke arah kualitatif. Memahami betul perbedaan secara substantif teori dengan model, bukan hanya akan memberi klarifikasi, tetapi juga memahami pula masing-masing istilah ilmiah itu dengan lebih komprehensif. Kajian dilakukan berdasarkan studi pustaka, dengan penulisan secara deskriptif kritis, diharapkan pula memberi ruang diskusi yang lebih dalam. Dengan demikian, tujuan penulisan artikel ini seperti disebutkan di atas akan lebih tajam dan signifikan (mencapai tingkat universe of discourse).
\end{abstract}

Kata kunci: model, teori, fungsi teori, fungsi model 


\section{PENDAHULUAN}

Hampir semua mahasiswa, bahkan ketika diuji saat sidang skripsi, tidak begitu mengerti perbedaan teori dengan model. Banyak di antara mereka juga tidak mengerti teori dan definisi. Beberapa di antara mereka bahkan belum memahami betul konsep-konsep pokok penelitian seperti variabel, konstruk, konsep, definisi, proposisi, asumsi, hipotesis, teori, dan hukum. Dalam tulisan ini tidak akan dibahas hal-hal tersebut secara keseluruhan. Yang jadi fokus telaahan tulisan ini adalah perbedaan teori dengan model karena hal ini yang kurang dipahami oleh mahasiswa akhir.

Bagaimana menjawab persoalan penelitian secara deduktif-teoretis ketika tidak memahami betul makna dari hal yang dijadikan acuan deduksinya. Padahal, hal inilah yang menjadi guide dan kerangka pelaksanaan penelitian di lapangan. Mungkin skripsi bisa selesai dikerjakan, tapi tidak dengan penghayatan yang memadai. Skripsi hanya tonggak yang harus dilalui oleh mahasiswa dalam mendapatkan gelar saja, tidak memberi kesan mendalam bagi pembuatnya. Kebanggaan mungkin ada, tapi kebanggaan telah menyelesaikannya bukan kebanggaan menguasai yang ditulisnya secara komprehensif terhubung dengan ilmu yang telah ditimba selama kuliah.

Berdasarkan hal itu, dengan tulisan ini diharapkan umum atau mahasiswa khususnya dapat memahami perbedaan model dan teori sehingga ketika menulis karya ilmiah, khususnya skripsi, bisa dengan tegas dan penuh penghayatan apa yang dijadikan dasar acuan hipotesisnya: model atau teori.

\section{Model Komunikasi}

\section{Definisi Model}

Menurut Deutsch dalam Severin dan Tankard (2008), "Model adalah struktur simbol dan aturan kerja yang diharapkan selaras dengan serangkaian poin yang relevan dalam struktur atau proses yang ada. Model sangat vital untuk memahami proses yang lebih kompleks”. Jadi, berdasarkan pandangan Deutsch, model merupakan struktur simbol dalam sebuah proses guna memahami proses yang sifatnya kompleks. Struktur ini bisa terlihat bila divisualisasikan.

Sedangkan menurut Severin and Tankard, (2008),

"Model didefinisikan sebagai representasi dunia nyata dalam bentuk yang teoretis dan disederhanakan. Model bukan alat untuk menjelaskan, tapi bisa digunakan untu membantu merumuskan teori. Model menyiratkan suatu hubungan yang sering dikacaukan dengan teori karena hubungan antara model dengan teori begitu dekat. Model memberi kerangka kerja yang bisa digunakan untuk mempertimbangkan satu masalah meskipun dalam versi awalnya model tidak akan membawa kita menuju prediksi yang berhasil”.

Dapat dipahami, bahwa model merupakan gambaran dunia nyata yang kompleks dan secara teoretis disederhanakan. Karena begitu dekat dengan teori, terutama dalam relasi antar unsur atau komponen yang bisa berupa konsep atau bahkan variabel, maka model bisa tersamar sebagai teori. Tapi, meskipun model bisa digunakan untuk mempertimbangkan dalam bentuk prediksi suatu masalah, berbeda dengan teori yang memang sejak awal sudah "meyakinkan” karena sudah teruji. Jadi model bisa digunakan untuk mempertimbangkan relasi variabel, tapi tidak sekuat teori dalam hal prediksi.

Sereno dan Mortensen dalam Dedy Mulyana (2007); "Model komunikasi merupakan deskripsi ideal mengenai apa yang dibutuhkan untuk terjadinya komunikasi”. Definisi ringkas dari Sereno dan Mortensen, justru bermakna luas. Model merupakan gambaran ideal tentang yang dibutuhkan untuk 
terjadinya komunikasi. Semua definisi model ini lebih kepada proses komunikasi dan hal-hal yang diperlukan untuk terjadinya proses tersebut.

Menurut Dedy Mulyana, (2007); "Model adalah representasi suatu fenomena, baik nyata atau abstrak dengan menonjolkan unsur-unsur terpenting fenomena tersebut. Sebagai alat untuk menjelaskan fenomena komunikasi, model mempermudah penjelasan tersebut”. Jadi model menurut Mulyana adalah wakilan dari gejala dengan menonjolkan unsur-unsur yang dianggap penting oleh pembuatnya. Aubrey Fisher dalam Mulyana, (2007) merumuskan, "Model adalah analogi yang mengabstrasikan dan memilih bagian dari keseluruhan unsur, sifat atau komponen yang penting dari fenomena yang dijadikan model. Model adalah gambaran informal untuk menjelaskan atau menerapkan teori”.

Fisher menganggap model sebagai analogi dari fenomena dengan memilih bagian, sifat atau komponen yang dianggap penting untuk diabstraksikan sebagai gambaran informal. McQuail dan Windahl (1981) menulis, "Model adalah penggambaran tentang suatu bagian atau sebuah realita yang sengaja dibuat sederhana dalam bentuk grafik”. Definisi McQuail dan Windahl ini yang lebih eksplisit bahwa model adalah gambar (bukan sekedar gambaran) berupa grafik tentang suatu bagian atau keseluruhan realita yang disederhanakan.

Berdasarkan definisi dan penjelasan beberapa ahli tersebut, model adalah visualisasi berupa grafik atau diagram tentang realita baik proses maupun struktur (di dalamnya juga terdapat teori dan fomula) yang disederhanakan agar mudah dipahami dengan menonjolkan unsur atau elemen yang dianggap penting. Model juga bisa jadi skema teori agar aplikasikan untuk diuji atau diturunkan menjadi proposisi. Jadi, model bisa berupa visualisasi dari proses, struktur, definisi, formula, bahkan teori agar sederhana dan mudah difahami sehingga bisa dijadikan acuan kerangka kerja.

Berikut ini model yang diturunkan dari definisi sekaligus formula: Model Formula Lasswel. (Model ini bisa juga dianggap menggambarkan proses komunikasi karena memperlihatkan urutan peristiwa dalam komunikasi dari komunikator hingga efek).

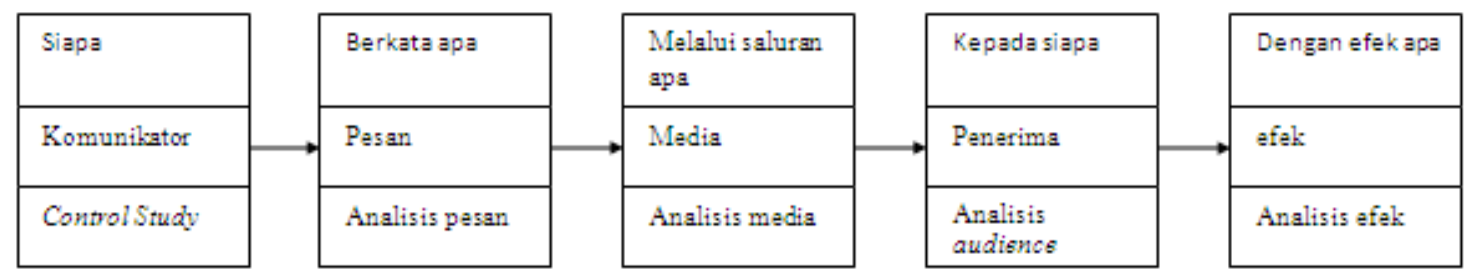

Gambar 1 Model Formula Lasswel

Sedangkan model yang menggambarkan teori bisa dilihat pada gambar berikut. Teori ini memperlihatkan unsur pesan sangat dominan dalam komunikasi (massa) sehingga dia seakan stimulus terhadap "makhluk” (manusia karena dianggap lemah maka disejajarkan dengan organisme lain) yang menghasilkan efek sesuai yang diharapkan komunikator.

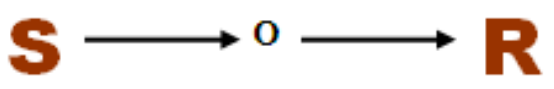

Gambar 2 S-R Theory

Model ini pun pada akhirnya menghasilkan teori yang sama sekali menghilangkan "organisme”, yakni S-R Theory, setelah The Powerfull Effects Model mencapai puncak kejayaannya pada tahun 1937 dengan adanya sandiwara radio Orson Wells, The Invasion from Mars. 
Contoh model yang menggambarkan proses komunikasi, dapat dilihat pada tiga model yang digambarkan berikut ini.

\section{Model Proses Komunikasi Linear Sederhana}

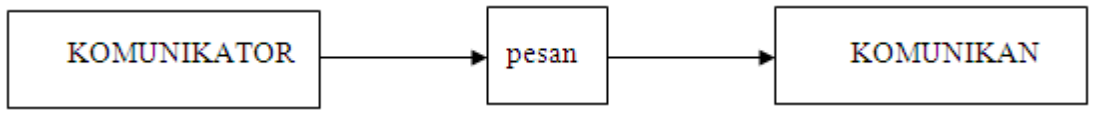

Gambar 3 Model Proses Komunikasi Linear Sederhana

Model tersebut menggambarkan proses komunikasi linear sederhana, yakni terpenuhinya "tiga unsur minimal" dari syarat terjadinya komunikasi menurut Wilbur Schramm dalam (McQuail dan Windahl 1981).

\section{Proses Komunikasi Linear Sederhana dengan Umpan Balik}

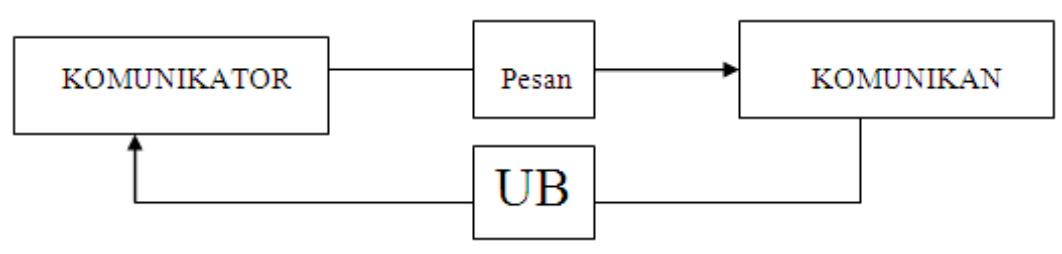

Gambar 4 Model Proses Komunikasi Linear Sederhana dengan Umpan Balik

Sedangkan gambar berikut merupakan model yang menggambarkan proses komunikasi sirkuler, model yang menempatkan posisi komunikator dan communicate (komunikan) sejajar. Baik komunikator dan communicate punya otoritas yang sama dalam komunikasi. Berbeda dengan dua model terdahulu, termasuk Model Lasswel, yang menganggap komunikator lebih tinggi, lebih punya otoritas, dari communicate.

\section{Model Komunikasi Sirkuler (W. Sachramm)}

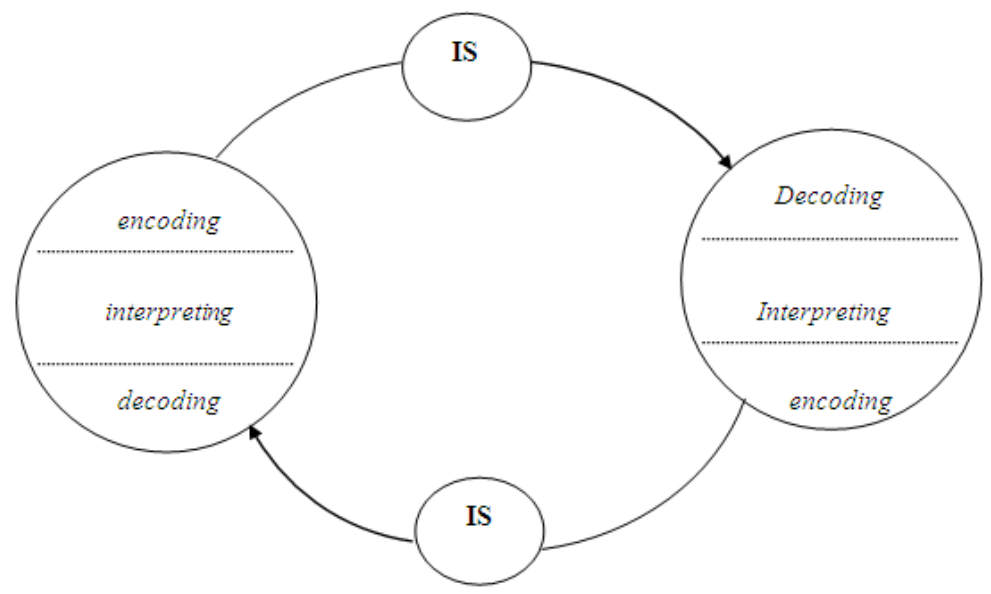

Gambar 4 Model Komunikasi Sirkuler (W. Sachramm) 


\section{Fungsi Model}

Fungsi adalah tugas pokok dari sesuatu. Jadi fungsi model berarti tugas pokok dari model. Menurut Deutsch dalam Severin and Tankard (2008), fungsi model adalah: (1) Mengorganisasi, yakni mengatur dan menghubungkan data yang tidak terlihat sebelumnya. (2) Heuristic, yakni memberi kemungkinan menuju metode baru yang belum dikenal. (3) Prediktif, yakni melakukan prediksi yang bersifat kuantitatif mengenai kapan dan seberapa banyak. (4) Pengukuran, data yang diperoleh dengan bantuan sebuah model bisa menjadi suatu ukuran baik sekedar ranking atau sekala rasio penuh.

Sedangkan menurut Gordon, Wiseman dan Larry Barker dalam (Mulyana, 2007), model komunikasi mempunyai tiga fungsi; pertama melukiskan proses komunikasi; kedua, menunjukkan hubungan visual; dan ketiga, membantu dalam menemukan dan memperbaiki kemacetan komunikasi.

\section{Teori Komunikasi}

\section{Definisi Teori}

Kerlinger (2004) Teori adalah seperangkat konstruk (konsep), batasan dan proposisi yang menyajikan suatu pandangan sistematis tentang fenomena dengan merinci hubungan-hubungan antar variabel dengan tujuan menjelaskan dan memprediksi gejala tersebut. Batasan di atas mengandung tiga hal, pertama, sebuah teori adalah seperangkat proposisi yang terdiri atas kontruks-konstruk yang terdefinisikan dan saling berhubungan. Kedua, teori menyusun antar hubungan seperangkat variabel (konstruk) dan dengan demikian merupakan suatu pandangan sistematis mengenai fenomenafenomena yang dideskripsikan oleh variabel-variabel itu. Akhirnya suatu teori menjelaskan fenomena. Penjelasan itu diajukan dengan cara menunjuk secara rinci variabel-variabel tertentu yang berkait dengan variable-variabel tertentu lainnya.

Menurut ahli lain, Teori adalah sebuah sistem konsep yang abstrak dan hubungan-hubungan konsep tersebut yang membantu kita untuk memahami sebuah fenomena. (West and Turner, 2008). Sedangkan menurut Turner dalam (West and Turner, 2008), teori adalah sebuah proses mengembangkan ide-ide yang membantu menjelaskan bagaimana dan mengapa suatu peristiwa terjadi. Menurutnya, teori mempunyai tingkat generalitas, sebagai berikut: (1) Teori dalam arti luas (grand theory); teori yang berusaha menjelaskan semua fenomena seperti komunikasi. Bertujuan untuk menjelaskan mengenai semua perilaku komunikasi dengan cara yang benar secara universal. (2) Teori dalam arti menengah (mid-range theory); teori yang berusaha untuk menjelaskan suatu aspek tertentu dari sebuah fenomena seperti komunikasi. Menjelaskan perilaku dari sekelompok orang dan bukannya semua orang. (3) Teori dalam arti sempit (narrow theory); teori yang berusaha menjelaskan suau aspek yang terbatas dari suau fenomena seperti komunikasi. Menekankan pada orang-orang tertentu pada situasi tertentu pula.

Littlejohn (1996:2) menyatakan,

"Any attempt to explain or represent an experience is a theory, an idea of how certain events happen... Our theories guide us in making decisions and taking actions, and they change from time to time as we observe new things acquire new perspectives. Our theories identify patterns of events in the environment so we know what to expect. They draw our attention to important aspects of everyday life. They help us decide what important and what is not. And they enable us to predict what will happen next."

Dia pun menjelaskan, "Theories of communication help us become more competent and adaptive (1996)”. Selain seperti yang dikemukakan para ahli tersebut, teori juga lahir setelah proses pengujian di lapangan (penelitian); maka teori merupakan pernyataan yang sudah teruji. Berdasarkan 
hal itu dan definisi para ahli tersebut, dapat disimpulkan bahwa teori adalah merupakan rumusan abstrak tentang relasi antar konsep yang telah teruji kebenarannya yang membantu kita memahami, memprediksi, dan mengontrol sebuah peristiwa.

\section{Fungsi Teori}

"The first function of theory is to organize and summarize knowledge. The second function is focusing. Third, theories clarify what is observed. Fourth, Theories offer an observational aid. The Fifth function of theories, to predict, is one of the most widely discussed purposes of scientific inquiry. The sixth theoretical function, the heuristic function, is also frequently discussed. Seventh theories serve an indispensable communicative function. The eighth function of theories is control. The final function of theory is the generative function. (Littlejohn.1996).

Mengacu pada Littlejohn, maka fungsi teori dapat dijelaskan sebagai berikut: (1) Fungsi mengorganisasikan dan menyimpulkan pengetahuan tentang sesuatu hal. Artinya, dalam mengamati realitas tidak boleh melakukannya secara sepotong-sepotong. Hasilnya akan berupa teori yang dapat dipakai sebagai rujukan atau dasar bagi upaya-upaya studi berikutnya. (2) Fungsi memfokuskan pada hal-hal atau aspek-aspek dari suatu objek yang diamati. Objek yang diamati itu harus jelas fokusnya. Teori pada dasarnya hanya menjelaskan tentang suatu hal bukan banyak hal. (3) Fungsi menjelaskan, bahwa teori harus mampu membuat suatu penjelasan tentang hal yang diamatinya. Penjelasan ini tidak hanya berguna untuk memahami pola-pola hubungan tetapi juga untuk menginterpretasikan peristiwaperistiwa tertentu. (4) Fungsi pengamatan, yaitu menunjukkan bahwa teori tidak saja menjelaskan tentang apa yang sebaiknya diamati, tetapi juga memberikan petunjuk bagaimana cara mengamatinya, karena itu teori yang baik adalah teori yang berisikan tentang konsep-konsep operasional. (5) Membuat prediksi, yaitu meskipun kejadian yang diamati berlaku pada masa lalu, namun berdasarkan data dan hasil pengamatan ini harus dibuat suatu perkiraan tentang keadaan bakal sambil mengamati hal-hal yang berkaitan dengan itu. Fungsi prediksi ini terutama sekali penting bagi bidang-bidang kajian komunikasi terapan seperti persuasi dan perubahan sikap, komunikasi organisasi, dinamika kelompok kecil, periklanan, hubungan masyarakat dan media massa. (6) Fungsi heuristik/heurisme. Aksioma umum menyebutkan bahwa teori yang baik adalah teori yang mampu merangsang penelitian dan upaya-upaya penelitian selanjutnya. (7) Fungsi komunikasi yang menunjukkan bahwa teori seharusnya tidak menjadi monopoli pencipta teori. Teori harus dipublikasikan, didiskusikan dan terbuka terhadap kritikan-kritikan. Dengan cara ini maka modifikasi dan upaya penyempurnaan teori akan dapat dilakukan. (8) Fungsi kontrol/mengawasi, yaitu bersifat normatif karena asumsi-asumsi teori dapat kemudian berkembang menjadi norma-norma atau nilai-nilai yang dipegang dalam kehidupan sehari-hari. Dengan perkataan, teori dapat berfungsi sebagai sarana pengendali atau pengontrol tingkah laku kehidupan manusia. (9) Fungsi generatif; terutama sekali menonjol di kalangan pendukung tradisi/aliran pendekatan interpretatif dan teori kritis. Menurut pandangan aliran ini, teori juga berfungsi sebagai sarana perubahan sosial dan kultural, serta sarana untuk menciptakan pola dan cara kehidupan baru.

\section{METODE}

Metode penelitian yang digunakan dalam artikel ini adalah kajian/telaah pustaka (literature studies). Metode ini digunakan, karena yang menjadi kajian adalah teori dan model, terutama untuk mendapatkan perbedaannya. Teori dan model adalah abstraksi dari realitas. Tampilan teori dan model hanya ada dalam dunia literatur yang merupakan dunia/realitas kedua sebagai hasil kajian dunia/realitas primer. 
Prosedur dalam kajian/penelaahan ini sebagai berikut: (1) Bahan-bahan pustaka yang berkaitan dengan teori dan model dikumpulkan. (2) Ditelaah satu persatu dari masing-masing pustaka tersebut tentang makna, pengertian, dan definisi dari teori dan model. (3) Supaya lebih komprehensif, juga di telaah fungsi dari teori dan model dari masing-masing literatur. (4) Hasil telaahan kemudian disimpulkan. (5) Penyajian dalam bentuk tulisan yang diperkaya dengan contoh model dan teori. Berdasarkan metode dan prosedur telaahan/kajian pustaka seperti itulah tulisan ini tersaji dengan bobot kritis kandungan pustaka berbagai sumber.

\section{HASIL DAN PEMBAHASAN}

Berdasarkan pembahasan di atas, jelas bahwa model bisa merupakan tampilan sekematis (visualisasi, gambaran nyata) dari teori, tapi teori bukanlah sebuah model. Namun, meskipun demikian, mengingat fungsi masing-masing, dalam penelitian kuantitatif keduanya bisa digunakan sebagai dasar (premis mayor) dalam deduksi. Keduanya bisa digunakan sebagai landasan hipotesis. Hanya saja, tarikan teori ke hipotesis menghasilkan proposisi (karena hubungan variabel yang ditarik berdasarkan hubungan konsep yang telah teruji benarannya), sedangkan tarikan model ke hipotesis tidak bisa dikatakan sebagai proposisi, melainkan masih asumsi (kecuali model dari teori).

Di sisi lain, sudah clear pula bahwa penelitian yang memerlukan hipotesis adalah penelitian (kuantitatif) korelasional, baik pengaruh, sebab akibat, resiprokal, atau pun determinasi. Penelitian deskriptif tidaklah terlalu memerlukan teori. Kalaupun diperlukan, teori hanya sebagai guide bukanlah landasan utama penelitian. Permasalahan yang perlu didiskusikan lebih lanjur adalah: (1) Penelitian apa dan yang bagaimana yang memerlukan teori yang melahirkan proposisi sebagai landasan hipotesis dan penelitian mana dan bagaimana yang cukup dengan menggunakan model saja yang melahirkan asumsi (kecuali model dari teori) sebagai landasan hipotesis. (2) Meskipun sudah dimaklumi bahwa hasil penelitian merupakan bahan dasar komulatif dan verifikatif untuk membentuk atau mempertahankan teori - artinya secara umum baik produk penelitian yang didasarkan pada teori atau pun pada model mempunyai kegunaan yang sama - namun secara sekuensial ketika hasil penelitian itu diperoleh, seberapa sahih hasil dari keduanya itu bisa dijadikan dasar pembuatan keputusan/kebijakan. (3) Apabila dihubungkan dengan bentuk karya ilmiah yang berupa tugas akhir mahasiswa di perguruan tinggi; siapakah yang dianggap berkompeten membentuk model (karena model hanya menggambarkan) lalu melahirkan asumsi sebagai landasan hipotesis: apakah kandidat doktor dengan disertasinya atau mahasiswa S2 bahkan S1 juga boleh berasumsi yang didasarkan pada model yang dibuatnya?

Hal tersebut perlu didiskusikan, mengingat tidak ada pedoman yang baku yang mengaturnya. Jika dibebaskan begitu saja maka bisa dibayangkan, dalam hal tugas akhir di perguruan tinggi, apabila skripsi didasarkan pada asumsi, selain membuat mahasiswa malas membaca literatur, juga akan melahirkan skripsi yang hanya didasarkan common sense yang dipunyai calon sarjana yang tentu kualitasnya tidak adequate. Di sisi lain, kalau dilarang, bagaimana dengan mahasiswa yang punya kemampuan tinggi dalam menangkap aksioma dari realitas sosial, apakah juga tidak boleh?

\section{SIMPULAN}

Model adalah visualisasi berupa grafik atau diagram tentang realitas baik proses maupun struktur (di dalam juga terdapat teori dan fomula) yang disederhanakan agar mudah dipahami dengan menonjolkan unsur atau elemen yang dianggap penting. Model juga bisa jadi skema teori agar applicable untuk diuji atau diturunkan menjadi proposisi. Jadi, model bisa berupa visualisasi dari proses, struktur, definisi, formula, bahkan teori agar sederhana dan mudah dipahami sehingga bisa dijadikan acuan kerangka kerja. 
Teori adalah rumusan abstrak tentang relasi antar konsep yang telah teruji kebenarannya yang membantu memahami, memprediksi, dan mengontrol sebuah peristiwa. Jadi, perbedaan model dan teori berdasarkan definisi adalah: (1) Model bersifat visual, teori hanya berupa pernyataan. Apabila teori tersebut divisualkan maka teori tersebut dimodelkan. Dengan kata lain, dia menjadi model. (2) Teori sudah teruji kebenrannya, sedangkan model belum tentu teruji kebenarannya. Bisa saja hanya skema yang mempermudah kerangka kerja atau apa yang mau dikerjakan (terutama dalam penelitian). Hanya model dari sebuah teorilah yang sudah teruji kebenarannya. (3) Karena model bisa berasal dari teori (teori yang divisualkan dalam bentuk gambar), maka model bisa saja diturunkan dari teori induk (grand theory) dan dianggap menggantikan mid-rank theory atau narrow/applied theory untuk menggantikan posisi teori tersebut apabila belum ada.

Sedangkan perbedaan antara model dan teori berdasarkan fungsi adalah: (1)Model dan teori bisa digunakan sebagai skema peneltian (karena teori dapat dimodelkan) sehingga dua-duanya bisa digunakan untuk memprediksi termasuk melahirkan hipotesis. Hanya saja, model sebagai landasan prediksi dan hipotesis tidaklah kuat karena belum teruji kebenrannya (keculai model yang berasal dari teori). Sedangkan teori sebagai landasan prediksi dan hipotesis mempunyai pijakan kokoh karena sudah teruji kebenrannya. (2) Model tidak bisa digunakan sebagai instrumen yang mempunyai fungsi kontrol, sedangkan teori memang berfungsi akhir sebagai ontrol terhadap peristiwa. (3) Meskipun model dan teori masing-masing punya fungsi heuristic, namun pada model tidak bisa langsung dianggap sebagai heuristik tentatif yang kokoh. Tidak demikian dengan teori. Justru teori yang baik (benar dan teruji) memang harus mempunyai fungsi heurisme yang kuat meskipun tetap tentatif karena ceteris peribus. (4) Secara praktis, perlu didiskusikan kesahihan hasil penelitian yang didasarkan pada teori dan yang didasarakan pada model sebagai pijakan dalam membuat kebijakan. Perlu didiskusikan pula batas-batas akademis dalam sebuah penelitian menyangkut siapa yang berwibawa merumuskan model sebagai dasar penelitiannya atau sebagai dasar hipotesis melalui asumsi: apakah calon atau kandidat S1, S2, atau S3 saja.

\section{DAFTAR PUSTAKA}

Kerlinger, F. N. (2004). Asas-Asas Penelitian Behavioral (terjemahan). Yogyakarta: Gadjah Mada University Press.

Littlejohn, W. S. (1996). Theories Of Human Communication (fifth edition). USA: Wadsworth Publishing Company.

McQuail, D., Windhal, S. (1985). Model-Model Komunikasi (terjemahan; Putu Laxman Pendit). Jakarta: Uni Primas,.

Mulyana, D. (2007). Komunikasi, Suatu Pengantar. Bandung: Remaja Rosda Karya.

Severin, W. J., Tankard, J. W. (2008). Teori Komunikasi, Sejarah, Metode dan Terapan di dalam Media Massa (Edisi Kelima). Jakarta: Kencana Media Group.

West, R., Turner, L. H. (2008). Pengantar Teori Komunikasi, Analisis dan Aplikasi (Introducing Communication Theory: Analysis and Application). Jakarta: Salemba Humanika. 